\title{
Correction to: Histological structure of Nannospalax xanthodon cochlea tissue
}

\author{
Esra Balcioglu ${ }^{1} \cdot$ Fatih Mehmet Gur ${ }^{2} \cdot$ Hatice Emel Gur ${ }^{1} \cdot$ Pınar Bilgici $^{1} \cdot$ Teoman Kankılıç $^{3}$ \\ Published online: 4 May 2021 \\ (C) Institute of Zoology, Slovak Academy of Sciences 2021
}

Correction to: Biologia.

https://doi.org/10.1007/s11756-021-00746-5

The article was published with an erroneous spelling of a contributor name. The name has been updated in the original article. The original article has been corrected.

Publisher's note Springer Nature remains neutral with regard to jurisdictional claims in published maps and institutional affiliations.

The online version of the original article can be found at https://doi.org/ 10.1007/s11756-021-00746-5

Fatih Mehmet Gur

histolog44@gmail.com

1 Department of Histology-Embryology, Faculty of Medicine, Erciyes University, 38280 Kayseri, Turkey

2 Department of Histology-Embryology, Faculty of Medicine, Nigde Omer Halisdemir University, 51240 Nigde, Turkey

3 Department of Biology, Faculty of Arts and Sciences, Nigde Omer Halisdemir University, 51240 Nigde, Turkey 